\section{Association of primary hyperparathyroidism and humoral hypercalcemia of malignancy in a patient with clear cell renal carcinoma}

\author{
Letícia da Silva Gomes', Carolina A. M. Kulak', Tatiana Munhoz \\ da Rocha Lemos Costa', Evandro Cezar Guerreiro Vasconcelos ${ }^{1,2}$, \\ Maurício de Carvalho', Victoria Zeghbi Cochenski Borba'
}

\begin{abstract}
${ }^{1}$ Serviço de Endocrinologia e Metabologia, Hospital de Clínicas da Universidade Federal do Paraná (SEMPR-UFPR), Curitiba, PR, Brazil ${ }^{2}$ Serviço de Cirurgia de Cabeça e Pescoço, Hospital de Clínicas, UFPR, Curitiba, PR, Brazil
\end{abstract}

Correspondence to:

Victória Zeghbi Cochenski Borba Av. Agostinho Leão Júnior, 285 80030-110 - Curitiba, PR, Brazil vzcborba@gmail.com

Received on Mar/23/2014 Accepted on May/29/2014

\begin{abstract}
SUMMARY
Hypercalcemia is found frequently in patients with cancer. Besides the etiology related to the malignancy, other causes should be considered in the differential diagnostic, as primary hyperparathyroidism, granulomatous diseases and the use of thiazide diuretics. We present a case report of a severe hypercalcemia due to a rare association and review the relevant literature. A female patient, 57 years old, sent to the Endocrinology Service of Hospital das Clínicas da Universidade do Paraná (SEMPR) in order to investigate severe hypercalcemia with frequent need of hospitalization. The patient was in chemotherapy treatment for recurrence of clear cell renal cancer. During the investigation she presented high level of parathyroid hormone (PTH) and parathyroid scintigraphy suggestive of hyperplasia/ adenoma of parathyroid, histopathological diagnosis was confirmed after parathyroidectomy. After surgery the patient presented undetectable levels of PTH. However, she continued with progressive increase of serum calcium, with no signs of bone metastases or change in vitamin D metabolism. The investigation showed high levels of PTH-related protein (PTHrP), leading us to the diagnosis of hypercalcemia of malignancy. The patient presented severe hypercalcemia due to the rare association of primary hyperparathyroidism and humoral hypercalcemia of malignancy due to secretion of PTHrP by tumor cells. The presence of isolated primary hyperparathyroidism, as a cause of hypercalcemia in cancer patients, has been described in approximately $5-10 \%$ of the patients. However, the association of primary hyperparathyroidism and humoral hypercalcemia of malignancy (which means with concomitant elevation of PTH and PTHrP) is rare, only three cases have been described in the literature. Arch Endocrinol Metab. 2015;59(1):84-8
\end{abstract}

\section{INTRODUCTION}

$\mathrm{H}$ ypercalcemia is a metabolic disorder, which can have different causes. Approximately $90 \%$ of the patients with an increase of serum calcium have the primary hyperparathyroidism or hypercalcemia of malignancy as a cause, being uncommon the association of both in the same patient (1). Other rare causes can be included like suprarenal failure, pheochromocyto$\mathrm{ma}$ and VIPoma; the use of drugs; increased bone resorption; prolonged immobilization; rhabdomyolysis; excessive synthesis of 1.25-dihydroxyvitamin $\mathrm{D}$; thyrotoxicosis; milk-alkali syndrome and familial hypocalciuric hypercalcemia (2).

According to the literature, 20 to $30 \%$ of cancer patients will eventually present hypercalcemia, which has been associated to a poor prognosis (3-5). Hypercalcemia of malignancy can be classified into 4 types: malignant humoral hypercalcemia $(80 \%)$, local osteolytic hypercalcemia $(20 \%)$, secretion of 1.25-dihydroxyvitamin D $(<$ $0.1 \%)$ and ectopic hyperparathyroidism $(<0.1 \%)(6)$.

During the evaluation of a patient with cancer and hypercalcemia, it is important to consider in the differential diagnosis other causes of hypercalcemia in addition to malignant ones (6). In a study that evaluated 133 patients with cancer and hypercalcemia, $8(6 \%)$ presented the diagnosis of primary hyperparathyroi$\operatorname{dism}(7,8)$.

In this paper we report a case of severe hypercalcemia due to the rare association of primary hyperparathyroidism (confirmed by laboratory tests, images, surgery and anatomopathological examination) and humoral hypercalcemia of malignancy due to secretion 
of parathyroid hormone-related protein ( $\mathrm{PTHrP}$ ) by the tumor cells.

\section{MATERIAL AND METHODS}

The description of this case was approved by the hospital's Ethics Committee on Human Research. A 57 years old female patient was admitted to the Service of Endocrinology of Hospital das Clínicas da Universidade Federal do Paraná, Curitiba (SEMPR), to investigate severe hypercalcemia. Her serum calcium level was up to $15 \mathrm{mg} / \mathrm{dL}$ with frequent need for hospitalization and limited quality of life. Five years ago she had a radical right nephrectomy and cavotomy for clear cell renal cancer that recurred three years later, currently she is undergoing chemotherapy treatment with interferon. There is no previous report of hypercalcemia, and her family history of endocrine diseases was negative. She denied supplemental calcium, vitamin D, vitamin A or the use of any medication that could lead to hypercalcemia.

At the admission, serum levels of parathyroid hormone $(\mathrm{PTH})$ was $281.8 \mathrm{pg} / \mathrm{mL}$ (normal range: $15-68,3 \mathrm{pg} / \mathrm{mL}$ ). Total calcium was $14,6 \mathrm{mg} / \mathrm{dL}$ (normal range: $8,9-10 \mathrm{mg} / \mathrm{dL}$ ). Inorganic phosphorus was $2,0 \mathrm{mg} / \mathrm{dL}$ (normal range: $2,3-4,7 \mathrm{mg} / \mathrm{dL}$ ). Table 1 summarizes the laboratory results. ${ }^{99} \mathrm{mTc}$ Sestamibi scintigraphy scan showed a lesion suggestive of hyperplasia/adenoma of right lower parathyroid gland (Figure 1). Patient was diagnosed with primary hyperparathyroidism (PHPT) and was re- ferred for surgery aiming improvement of her quality of life, control of hypercalcemia and decreasing number of hospitalizations. The PHPT was confirmed by the histopathological examination of parathyroidectomy material, consistent with an adenoma of parathyroid gland.

Patient improved clinically after surgery, her PTH level was undetectable and her serum calcium decreased, although no full normalization was observed. At the follow up she presented a progressive increase of serum calcium level despite low levels of PTH. None bone metastatic lesion was seen at the scintigraphy scan, which could justify the persistent high calcium levels. Serum levels of 1.25-dihydroxyvitamin D3 and of $25-\mathrm{OH}$-vitamin $\mathrm{D}$ were $21.6 \mathrm{pg} / \mathrm{mL}$ (normal range: $18-78 \mathrm{pg} / \mathrm{mL}$ ) and $10.8 \mathrm{ng} / \mathrm{mL}$ (normal range: 30 - $100 \mathrm{ng} / \mathrm{mL}$ ), respectively. The serum PTH related protein (PTH-rP) level was 4,6 pmol/L (normal range: $<2$ pmol/L), compatible with humoral hypercalcemia of malignancy.

\section{RESULTS AND DISCUSSION}

We present a case of severe hypercalcemia due to a rare association of primary hyperparathyroidism and humoral hypercalcemia of malignancy due to secretion of PTHrP by renal cell carcinoma.

Hypercalcemia is a metabolic disorder caused by various diseases. In the mild hypercalcemia the serum calcium values are between $11-11.5 \mathrm{mg} / \mathrm{dL}$.

Table 1. Summary of the Laboratory Results during the entire follow-up

\begin{tabular}{|c|c|c|c|c|}
\hline Laboratory findings & Admission & 1 Week after surg. & 3 Months post surg. & Normal range \\
\hline Albumin $(\mathrm{g} / \mathrm{dL})$ & 3,7 & 3,6 & 3,4 & $3,5-5,0$ \\
\hline Calcium (mg/dL) & 14,6 & 10 & 12,7 & $8,9-10$ \\
\hline Corrected calcium (mg/dL) & 14,8 & 10,3 & 13,2 & \\
\hline Ionized calcium (mmol/l) & 1,77 & 1,31 & - & $1,12-1,32$ \\
\hline Urinary clacium 24 hours (mg/24 h) & $109,2(2,600 \mathrm{~mL})$ & - & $113(1,000 \mathrm{~mL})$ & $100-300$ \\
\hline Inorganic phosphorus (mg/dL) & 2,0 & 3,7 & 3,2 & $2,3-4,7$ \\
\hline PTH (pg/mL) & 281,8 & 7,8 & $<5,0$ & $15-68,3$ \\
\hline PTHrP (pmol/l) & - & - & 4,6 & $<2,0$ \\
\hline Creatinine (mg/dL) & 2,2 & 1,6 & 1,8 & $0,57-1,11$ \\
\hline 1,25-dihydroxyvitamin D3 (pg/mL) & - & - & 21,6 & $18-78$ \\
\hline 25-OH-vitamin D (ng/mL) & - & - & 10,8 & $30-100$ \\
\hline Urea (mg/dL) & 47 & 47 & 56 & $21-43$ \\
\hline Magnesium (mg/dL) & 2,1 & 1,9 & 2,4 & $1,6-2,6$ \\
\hline Alkaline phosphatase (U/l) & 86 & - & 142 & $40-150$ \\
\hline
\end{tabular}

PTH: parathyroid hormone; PTHrP: parathyroid hormone related protein; Surg.: parathyroidectomy surgery of right lower parathyroid gland. 

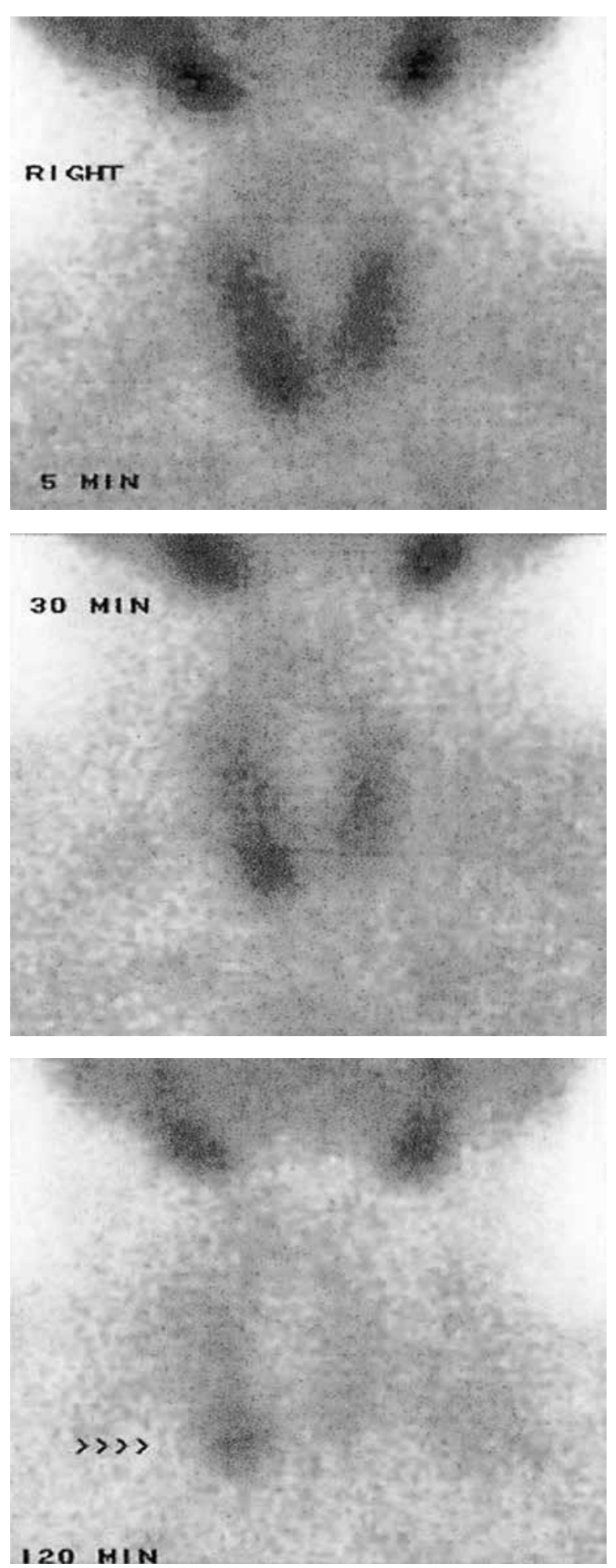
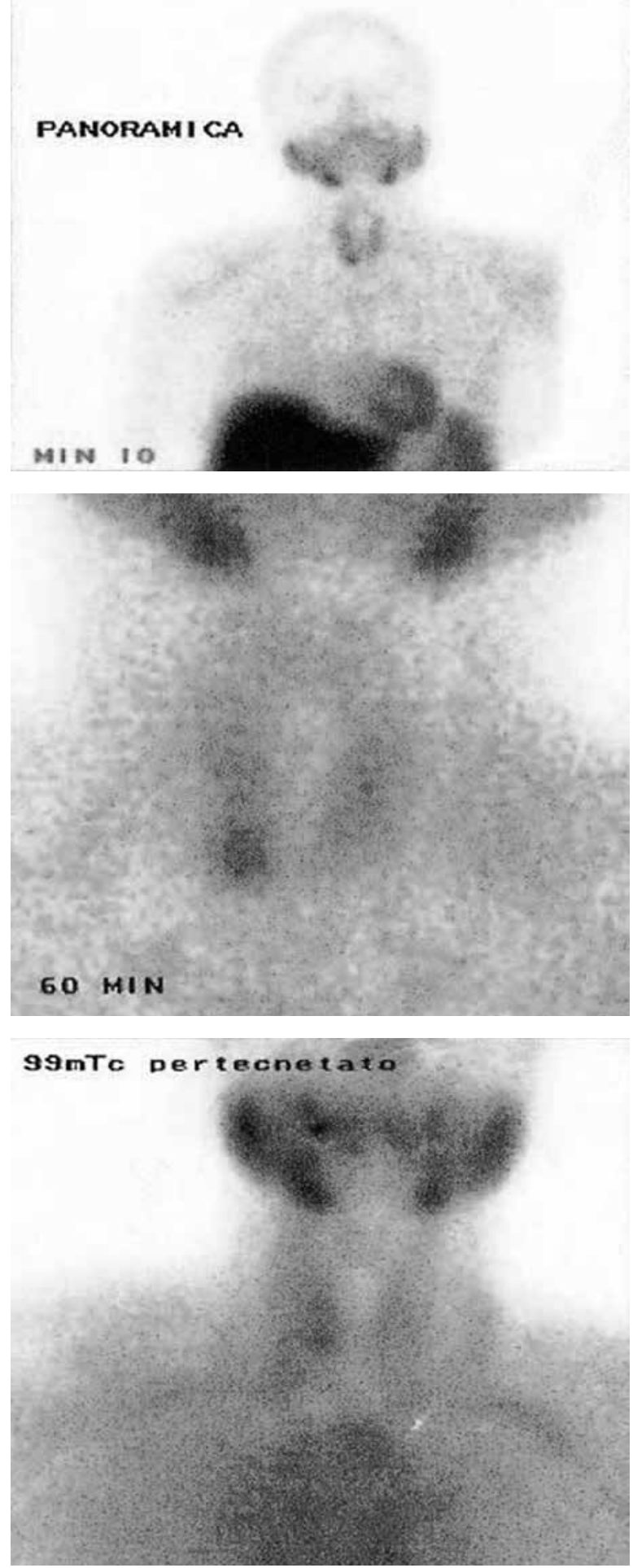

Figure 1. Parathyroid scintigraphy showing a lesion suggestive of hyperplasia/adenoma of lower right parathyroid.

It is generally asymptomatic and it is only detected by routine measurement of calcium, rarely is described moderate neuropsychiatric symptoms. Calcium levels higher than 12 and $13 \mathrm{mg} / \mathrm{dL}$ can cause lethargy, stupor and gastrointestinal symptoms. A serious hypercal- cemia has serum calcium levels substantially elevated between 15 and $18 \mathrm{mg} / \mathrm{dL}$, it is considered a medical emergency due to the risk of cardiac arrest and coma (6). Hypercalcemia and its complications have major impact on patients' quality of life. That is why the 
search for the etiology of hypercalcemia in cancer patients must be pursued and properly treated, even in advanced disease, as the patient described.

Fierabracci and cols detected seven cases of primary hyperparathyroidism studying 100 women with less aggressive breast cancer, suggesting routine measurement of PTH levels in patients with cancer and hypercalcemia in order to rule out this hypothesis (9).

The serum PTH levels are suppressed in the vast majority of hypercalcemias associated with malignancy. In this specific case, the high level of PTH was what prompted the initial suspicion of primary hyperparathyroidism as the cause of hypercalcemia. The dosage of PTHrP is usually performed only in cases of uncertain diagnosis. Interestingly a Chinese study evaluated, PTH and PTHrP in 178 patients hospitalized with hypercalcemia, 93 patients had hypercalcemia of malignancy and in seven an association with primary hyperparathyroidism was present, suggesting that. PTH and PTHrP should be measured routinely (10).

Isolated primary hyperparathyroidism as the cause of hypercalcemia of cancer patients has been described in 5 to $10 \%$ of the patients, but the association of primary hyperparathyroidism with humoral hypercalcemia of malignancy are rare.

Besides the Chinese study mentioned before (10), in the present research there were only 3 references of this association: a 65 year-old woman with a clear cells endometrial cancer (11); a 47 year-old man with carcinoma in the external manubrium (12); and a patient with multiple endocrine neoplasia type 1 and a neuroendocrine pancreas tumor (13).

The humoral hypercalcemia of malignancy is caused by the secretion of a peptide related to the parathormone (PTHrP) by the tumor cells. This peptide has homology with PTH in its amino-terminal sequence, what allows it to act in the PTH-1 receptor (PTHIR), being able to increase bone reabsorption and the renal retention of calcium. PTHrP is usually present in several organs and tissues, and is essential to life, although it is usually in non-detectable levels. When it is produced in large amounts by tumor cells, it can lead to a severe hypercalcemia. The levels of 1.25-dihydroxyvitamin D are usually low, since its molecule does not stimulate its production, as it was observed in our case (14).

Almost any kind of tumor can lead to this syndrome, the most frequent are squamous cell tumors (head and neck, esophagus, cervix, lung, and pancreas), renal cell carcinoma, bladder, breast, ovary, endometrium and lymphomas associated with HTLV-I virus. We could not find in the literature other reports of the association of humoral hypercalcemia of malignancy and primary hyperparathyroidism in patients with clear cell renal cancer, besides this case.

Interferon therapy has been related to changes in bone mass, but not to calcium metabolism. Some studies demonstrated gain of bone mass after treatment with interferon in patients with chronic hepatitis, systemic mastocytosis and thrombocythemia (15-17). In patients being treated for cancer there are no reports of this association.

The patient described had a previous diagnosis of recurrence of renal cell cancer and presented with hypercalcemia with high intact $\mathrm{PTH}$, a diagnosis of primary hyperparathyroidism was confirmed after the surgery and anatomopathological evaluation. Undetectable levels of PTH indicated a surgical cure, however, there was no normalization of serum calcium levels, suggesting the diagnosis of humoral hypercalcemia of malignancy, which was confirmed by the dosage of PTHrP. Unlike expected in isolated primary hyperparathyroidism, patient had low level of 1.25 dihydroxyvitamin D3 (18).

Considering the high cost and the difficulty of PTHrP dosage, its measurement routinely in patients with cancer and hypercalcemia is controversial. In cases of high suspicion of hypercalcemia of malignancy, when PTH level is low, there is a high chance that the cause is a humoral hypercalcemia of malignancy and the clinical management will not be very different after the laboratory confirmation of the diagnosis. However, in those cases where there is advanced malignant disease with a diagnosis of primary hyperparathyroidism in which surgical treatment could be indicated to improve patient's quality of life, PTHrP dosage may guide better the procedure and predict the behavior of calcemia after-surgery. More studies with larger number of patients would help to confirm this hypothesis, although the rarity of the association would be a limiting factor to this kind of study.

In summary, this report describes hypercalcemia in a 57-year-old woman with renal clear cell cancer that showed calcium elevation due to a simultaneous increase of PTH and PTHrP, indicating a rare association of primary hyperparathyroidism and humoral hypercalcemia of malignancy. This case highlights the importance of an appropriate biochemical assessment to patients with hypercalcemia, especially those with a history of malignant disease. 
Disclosure: no potential conflict of interest relevant to this article was reported.

\section{REFERENCES}

1. Walls J, Ratcliffe WA, Howell A, Bundred NJ. Parathyroid hormone and parathyroid hormone related protein in the investigation of hypercalcemia in two hospital populations. Clin Endocrinol (Oxf). 1994;41(4):407-13.

2. Jacobs TP, Bilezikian JP. Clinical review: Rare causes of hypercalcemia. J Clin Endocrinol Metab. 2005;90(11):6316-22.

3. Horwitz MJ, Stewart AF. Humoral hypercalcemia of malignancy. In: Favus MF, ed. Primer on the metabolic bone diseases and disorders of mineral metabolism. 5th ed. Washington D.C.: American Society for Bone and Mineral Research; 2003. p. 246-50.

4. Clines GA, Guise TA. Hypercalcemia in hematologic malignancies and in solid tumors associated with extensive localized bone destruction. In: Favus MJ, ed. Primer on the metabolic bone diseases and disorders of mineral metabolism. 5th ed. Washington D.C.: American Society for Bone and Mineral Research; 2003. p. 251-6.

5. Ralston SH, Gallacher SJ, Patel U, Campbell J, Boyle IT. Cancerassociated hypercalcemia: morbidity and mortality: clinical experience in 126 treated patients. Ann Intern Med. 1990;112:499-504.

6. Stewart AF. Hypercalcemia associated with cancer. N Engl J Med. 2005;352:373-9.

7. Godsall JW, Burtis WJ, Insogna KL, Broadus AE, Stewart AF. Nephrogenous cyclic AMP, adenylate cyclase-stimulating activity, and the humoral hypercalcemia of malignancy. Recent Prog Horm Res. 1986;42:705-50.

8. Aznar E, Marti R, Perez P, Palau J, Victoria J, Hidalgo V, et al. Hipercalcemia de origen tumoral: estudio de 133 casos. Rev Diagn Biol. 2001;50(1).

9. Fierabracci P, Pinchera A, Miccoli P, Conte PF, Vignali E, Zaccagnini $M$, et al. Increased prevalence of primary hyperparathyroidism in treated breast cancer. J Endocrinol Invest. 2001;24(5):315-20.
10. Lee JK, Chuang MJ, Lu CC, Hao LJ, Yang CY, Han TM, et al. Parathyroid hormone and parathyroid hormone related protein assays in the investigation of hypercalcemic patients in hospital in a Chinese population. J Endocrinol Invest. 1997;20(7):404-9.

11. Richey DS, Welch BJ. Concurrent primary hyperparathyroidism and humoral hypercalcemia of malignancy in a patient with clear cell endometrial cancer. South Med J. 2008;101(12):1266-8.

12. Gallacher SJ, Fraser WD, Farquharson MA, Logue FC, McArdle C, Boyle IT, et al. Coincidental occurrence of primary hyperparathyroidism and cancer-associated hypercalcemia in a middle-aged man. Clin Endocrinol (Oxf). 1993;38:433-7.

13. Milanesi A, Yu R, Geller SA, Burton D, Deftos LJ, Wolin EM. Concurrent primary hyperparathyroidism and humoral hypercalcemia of malignancy in a patient with multiple endocrine neoplasia type 1. Pancreas. 2011;40(4):634-7.

14. Testini M, Gurrado A, Lissidini G, Piccinni G, Greco L, Basile F, et al. Parathyroid hormone-related peptide and primary hyperparathyroidism. Front Biosci (Schol Ed). 2010;2:299-312.

15. Redondo-Cerezo E, Casado-Caballero F, Martin-Rodriguez JL, Hernandez-Quero J, Escobar-Jimenez F, Gonzalez-Calvin JL. Bone mineral density and bone turnover in non-cirrhotic patients with chronic hepatitis $C$ and sustained virological response to antiviral therapy with peginterferon-alfa and ribavirin. Osteoporos Int. 2014;25(6):1709-15.

16. Laroche M, Bret J, Brouchet A, Mazières B. Clinical and densitometric efficacy of the association of interferon alpha and pamidronate in the treatment of osteoporosis in patients with systemic mastocytosis. Clin Rheumatol. 2007;26(2):242-3.

17. Kusec R, Kusec V, Gisslinger B, Woloszczuk W, Gisslinger H. Bone metabolism during interferon-alpha treatment of essential thrombocythemia. Wien Klin Wochenschr. 2004;116(1-2): 37-41.

18. Burtis WJ, BradyTG, Orloff JJ, Ersbak JB, Warrell RP Jr, Olson BR, et al. Immunochemical characterization of circulating parathyroid hormone-related protein in patients with humoral hypercalcemia of cancer. N Engl J Med. 1990;322:1106-12. 